\title{
TANZANIA ONSHORE PALEOGENE INTEGRATED CORING (TOPIC)
}

Paul Pearson (Cardiff University, UK)

Ellen Thomas (Wesleyan and Yale University, USA)

\section{US participants:}

Gabe Bowen (University of Utah), Melissa Berke (University of Notre Dame), Sarah Feakins (University of Southern California), Matt Huber

(University of New Hampshire)

28 participants other countries 
http://www.icdp-online.org/projects/world/a frica/tanzania/

\section{TANZANIA ONSHORE PALEOGENE INTEGRATED CORING (TOPIC)}

\section{African Environmental History}

Deeper into the water: from lakes to the ocean Deeper in time: 60-30 Ma To warmer (greenhouse) climates 
http://www.icdp-online.org/projects/world/a frica/tanzania/

\section{TANZANIA ONSHORE PALEOGENE INTEGRATED CORING}

(TOPIS) goals?

PAST CLIMATE OF THE EARTH- what do we know and how do we know it?

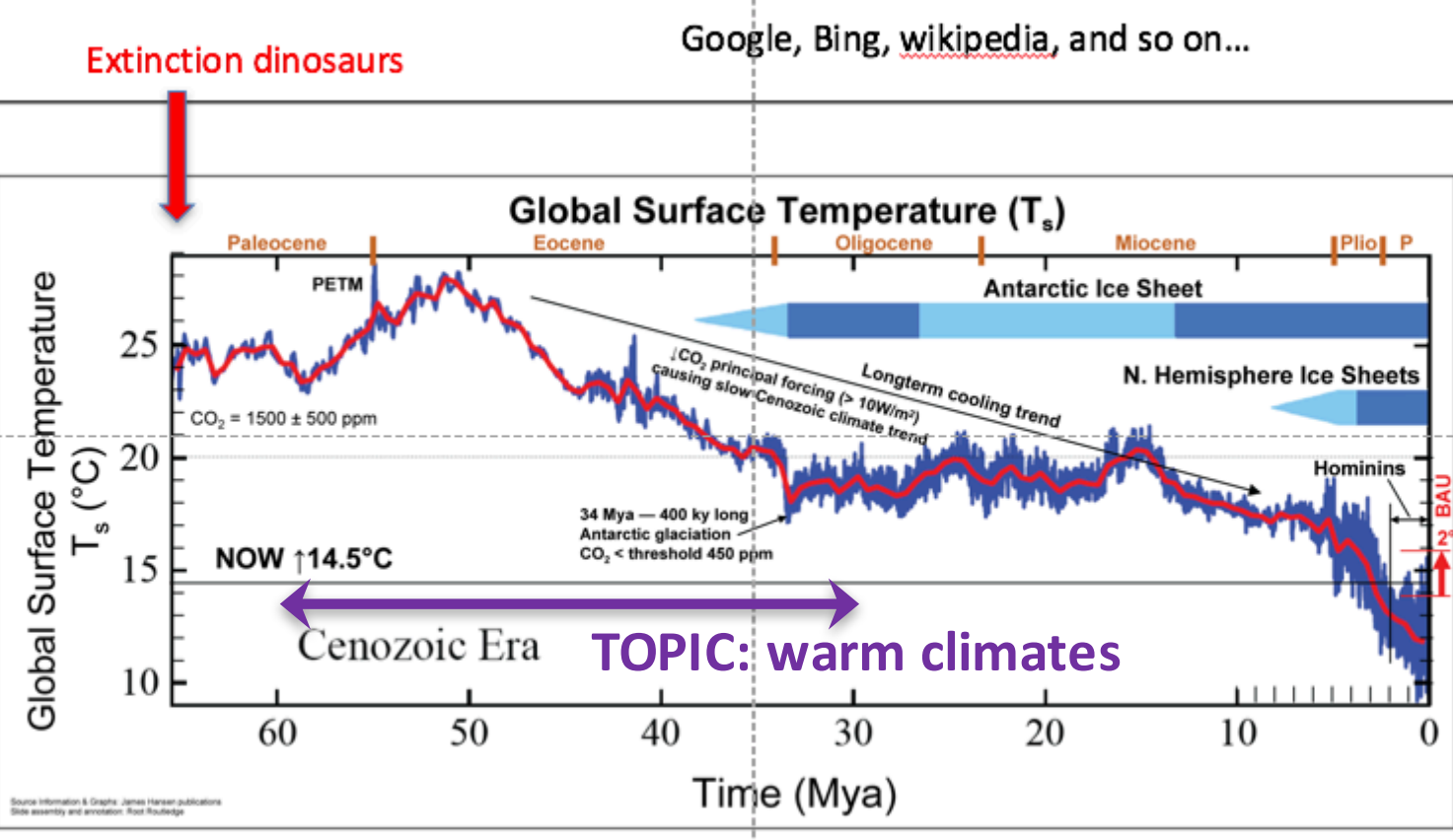

http://www.alpineanalytics.com/Climate/DeepTime.html

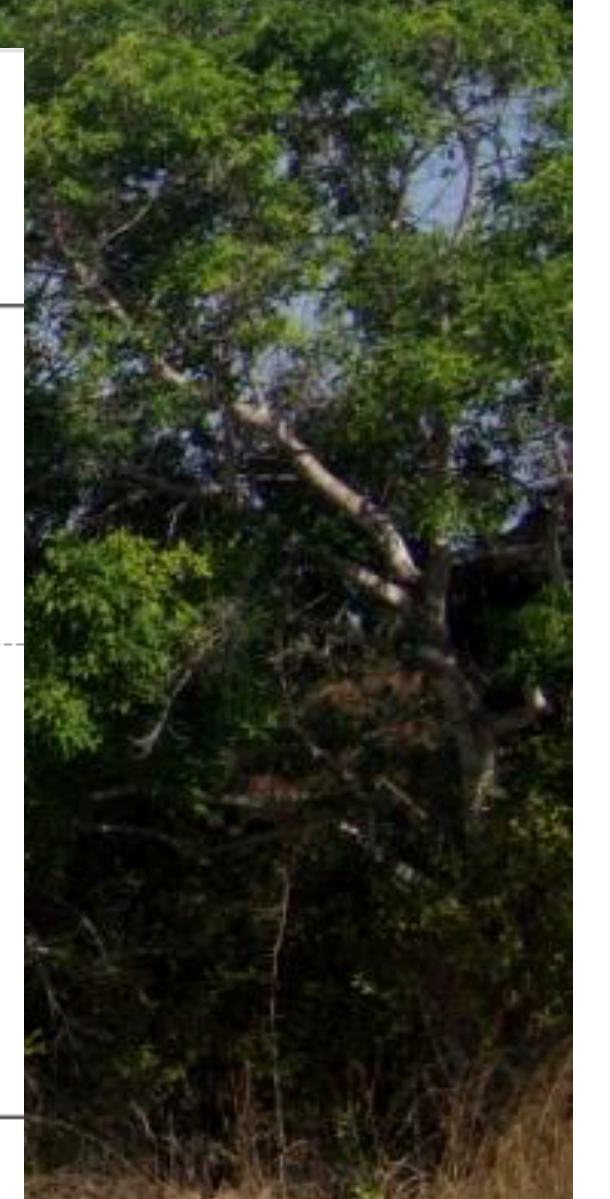




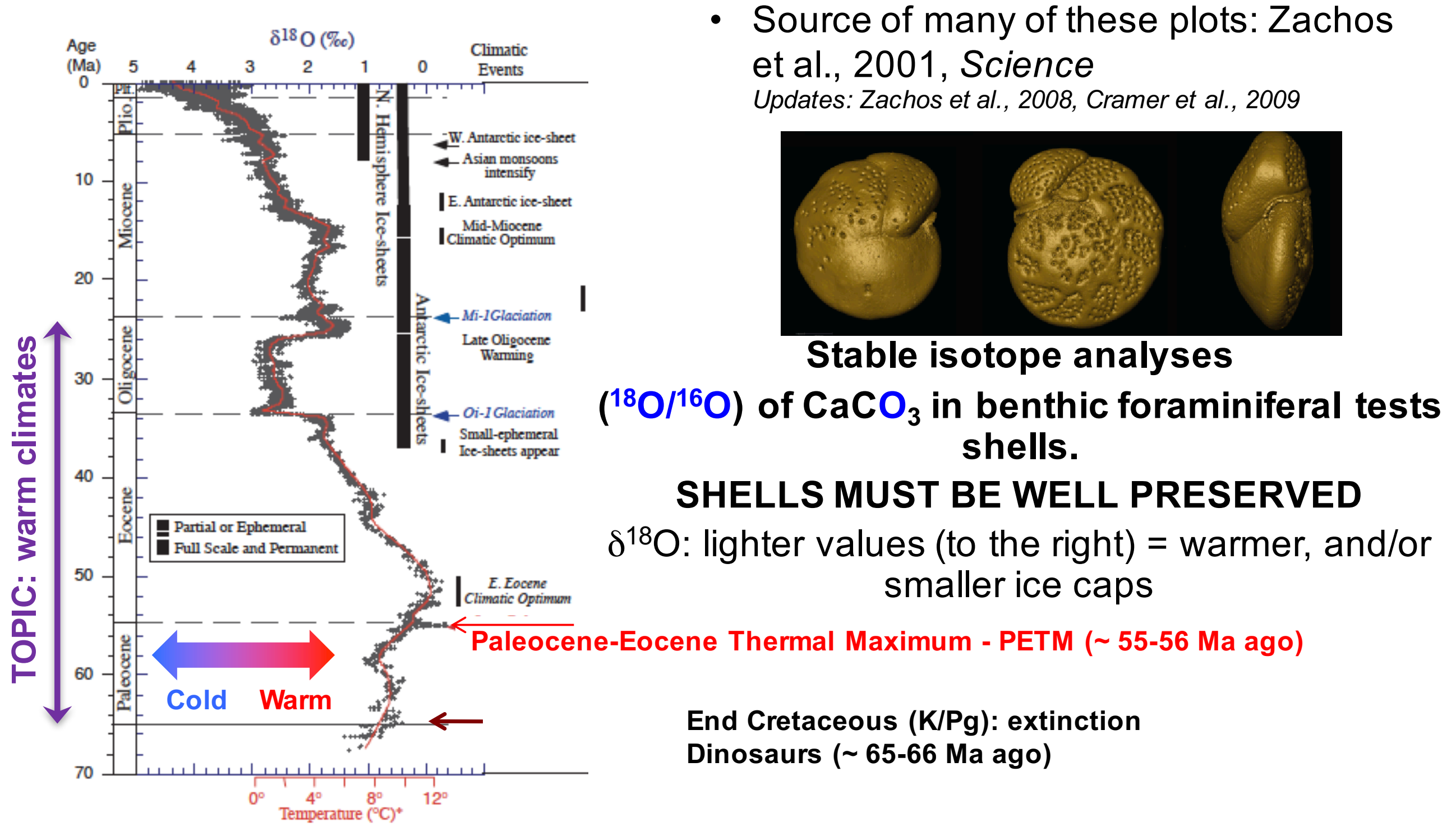




\section{'Cool Tropics Paradox':}

\section{N. Shackleton \& A. Boersma}

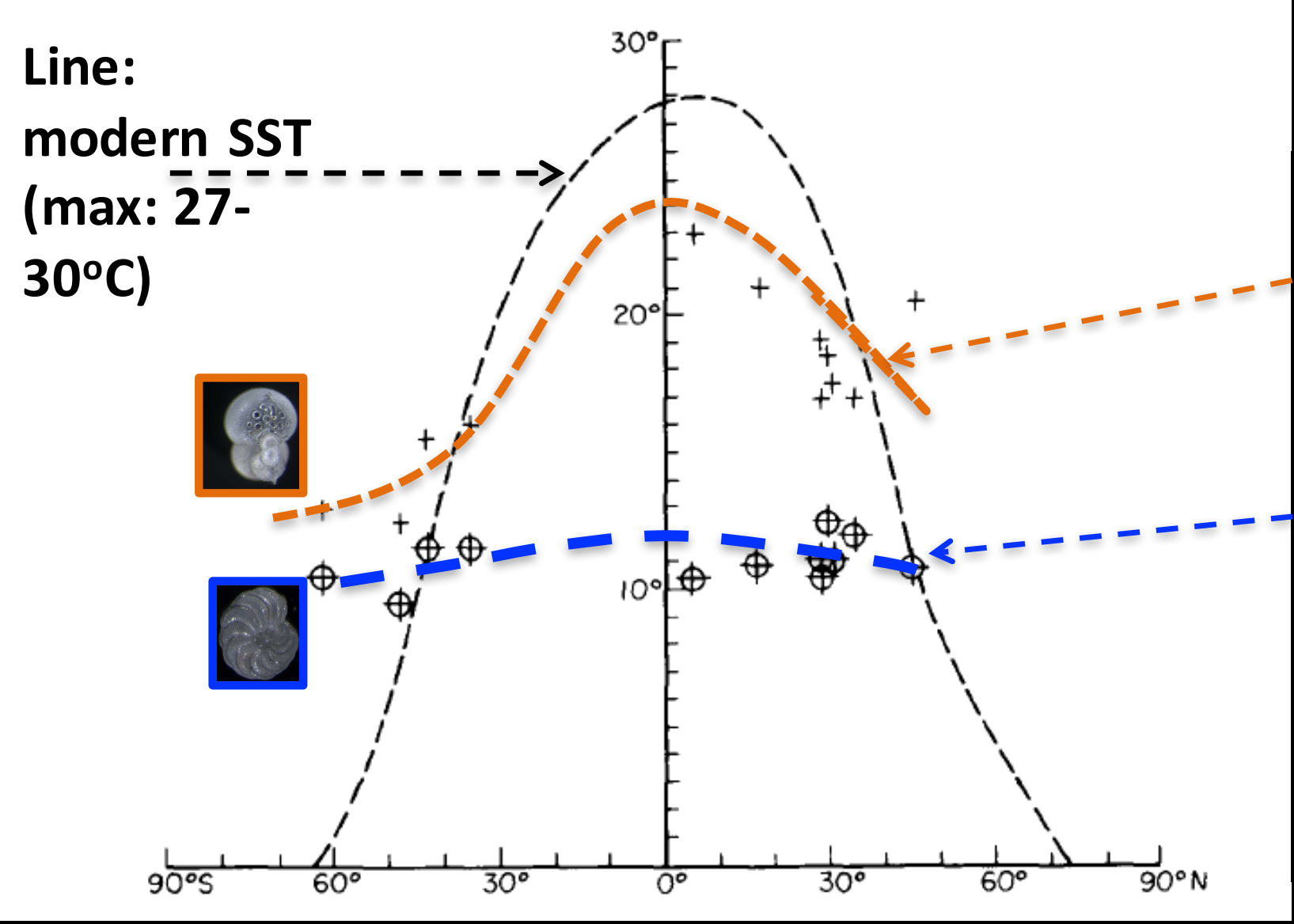

tropical sea surface

temperatures appeared cool while poles were very warm

Crosses, orange line: early Eocene Sea Surface Temperature.

Circles with cross, blue line: bottom water temperature

Shackleton \& Boersma, 1981

Planktonic foraminifera fall to sea floor - diagenesis/recrystallization in cold water 

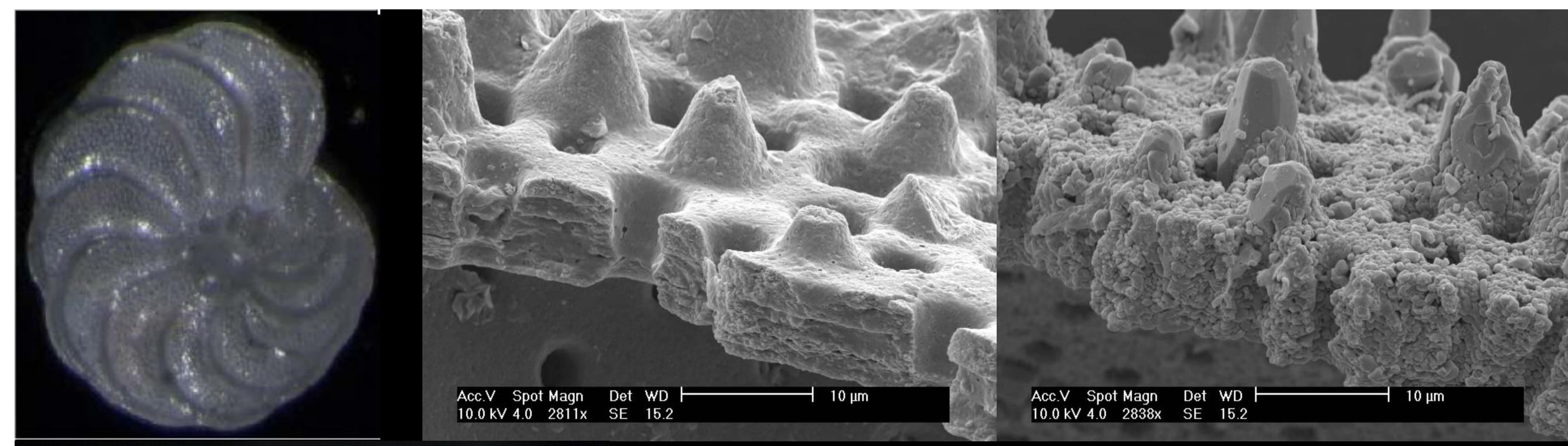

Tanzania (clay-rich sediment) ODP Site 865 (calcareous ooze) WHY TANZANIA? Superb microfossil preservation in clay rich sediment $\left(\mathrm{CaCO}_{3}\right.$, organic material)

Walter Harry Blow (1924-1972): collection of planktonic foraminifera donated to Natural History Museum London by BP, 1998 


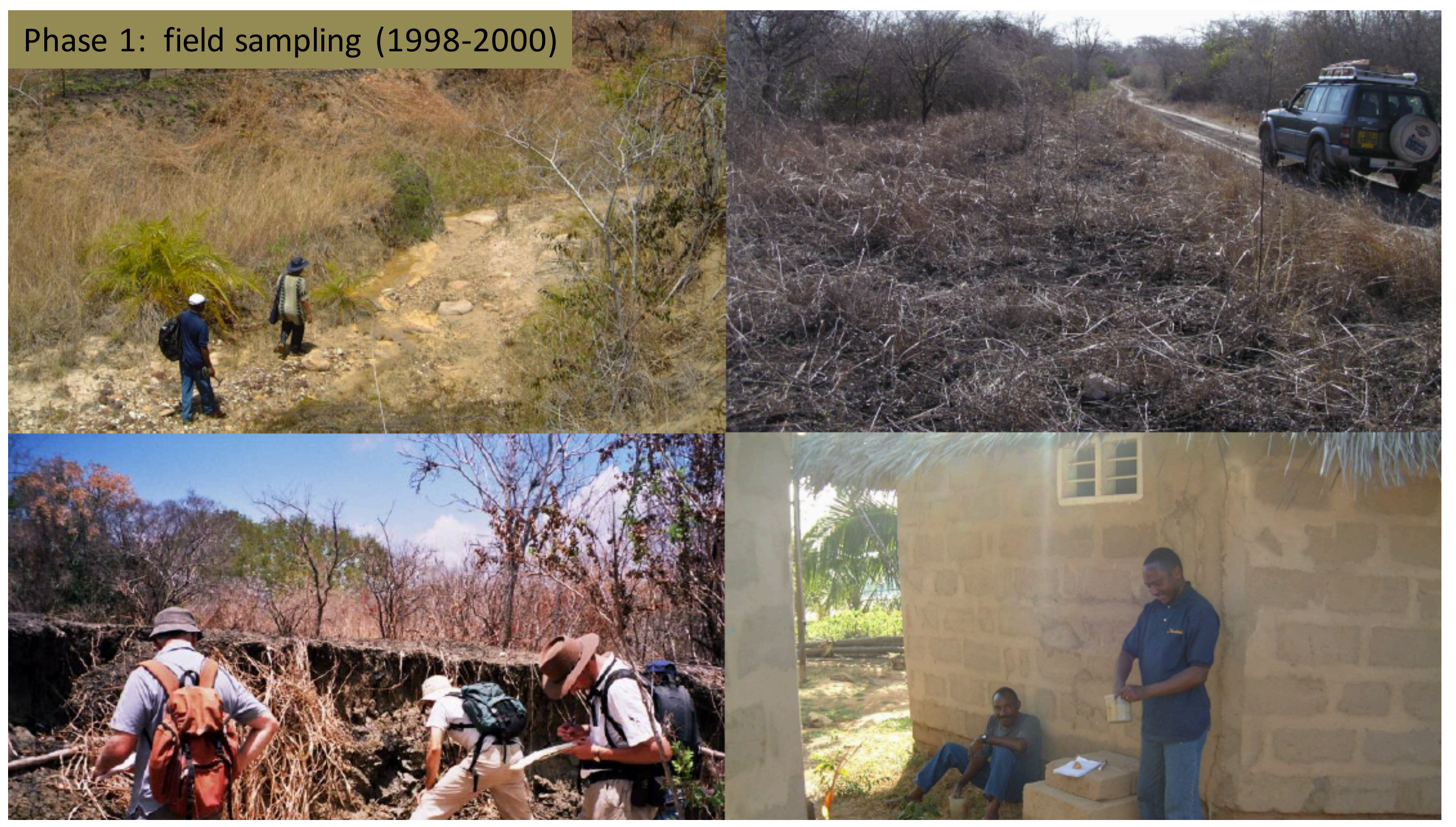


outcrop sampling: stable isotope proxies on foraminifera

\section{Warm tropical sea surface temperatures in the Late Cretaceous and Eocene epochs}

Paul N. Pearson ${ }^{\star}$, Peter W. Ditchfield ${ }^{\star}$, Joyce Singano $\dagger$, Katherine G. Harcourt-Brown ${ }^{\star}$, Christopher J. Nicholas $\ddagger$, Richard K. Olsson $\S_{\text {, }}$ Nicholas J. Shackleton\| \& Mike A. Hall||

NATURE| VOL $413 \mid 4$ OCTOBER $2001 \mid$ www.nature.com

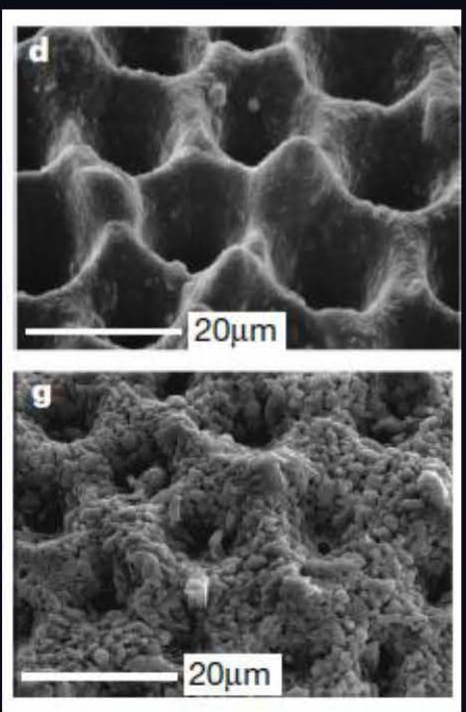

Tropical Sea Surface Temperatures at least $28-32^{\circ} \mathrm{C}$ (instead of 15$\left.23^{\circ} \mathrm{C}\right)$

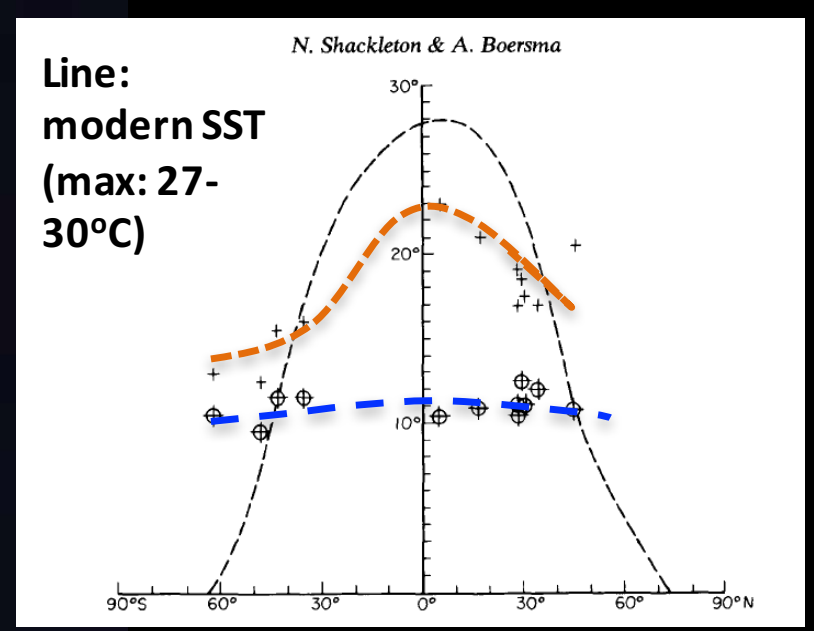

Crosses, orange line: early Eocene Sea Surface Temperature. Circles with cross, blue line: bottom water temperature Shackleton \& Boersma, 1981 


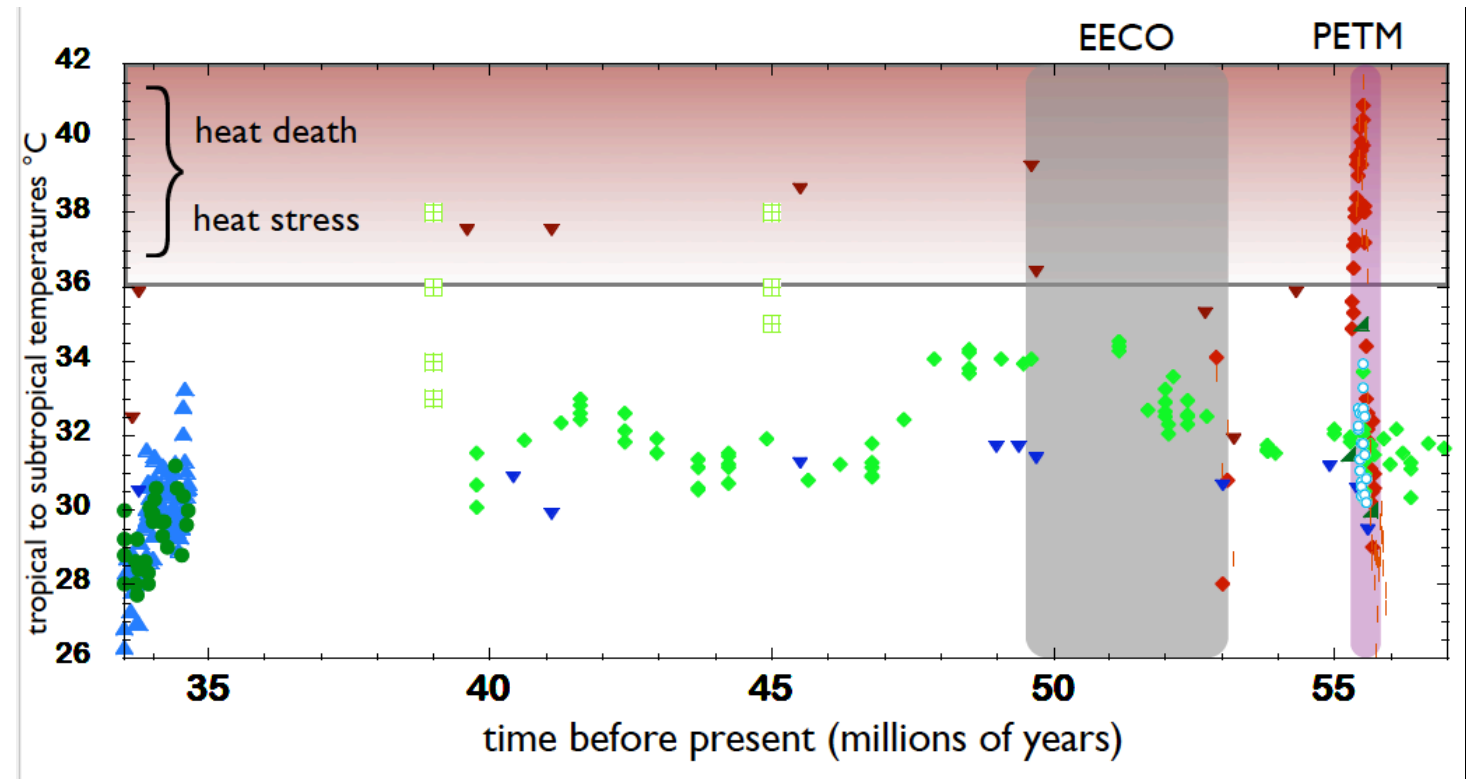

Low

latitudes data poor (Sagoo et al., 2013, Phil Trans. Roy. Soc.)

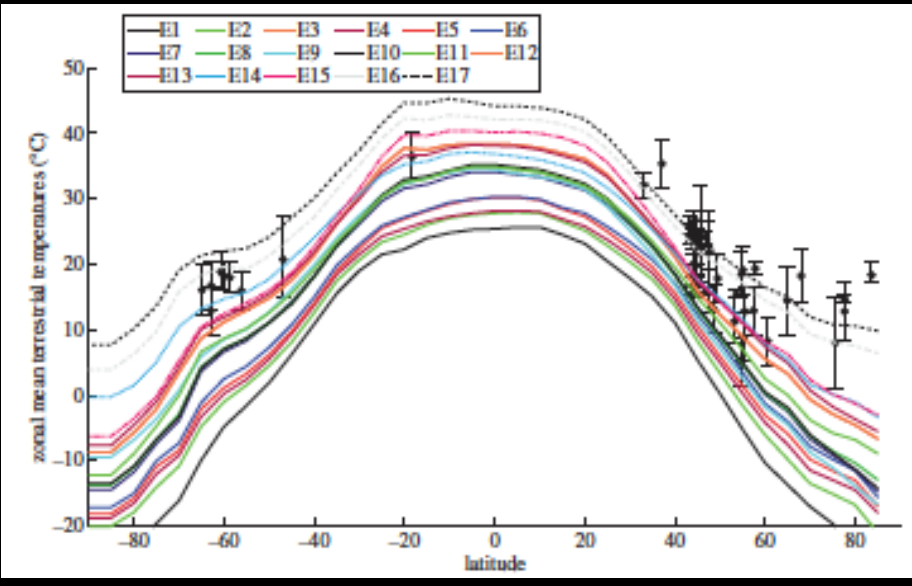

Did low latitudes get too hot for many life forms during PETM, other hyperthermals? Huber, 2008, Nature

Data from Tanzania (Aze et al., 2014, Geology) and Nigeria (Frieling et al., 2017) suggest they may have been.

\begin{tabular}{|c|c|c|c|}
\hline \multirow{3}{*}{$\begin{array}{l}\delta^{18} \mathrm{O} \text { temperature } \\
\text { correction factors }\end{array}$} & \multicolumn{3}{|c|}{ Kim and O'Neil (1997) } \\
\hline & Pre-PETM & PETM & Lowest $\delta^{18} \mathrm{O}$ \\
\hline & $\delta^{18} \mathrm{O}-3.38 \%$ & $\delta^{18} \mathrm{O}-4.04 \%$ & $\delta^{18} \mathrm{O}-5.14 \%$ \\
\hline $\begin{array}{l}\text { No latitude or } \\
\mathrm{pH} \text { correction }\end{array}$ & 26.3 & 29.6 & 35.4 \\
\hline $\begin{array}{l}\text { Latitude correction, } \\
\text { no pH correction }\end{array}$ & 30.5 & 34.0 & 39.9 \\
\hline $\begin{array}{l}\text { Latitude correction, } \\
\mathrm{pH} \text { correction }-0.25\end{array}$ & $\mathrm{~N} / \mathrm{A}$ & 35.9 & 41.9 \\
\hline $\begin{array}{l}\text { Latitude correction, } \\
\mathrm{pH} \text { correction }-0.45\end{array}$ & $\mathrm{~N} / \mathrm{A}$ & 37.4 & 43.4 \\
\hline
\end{tabular}




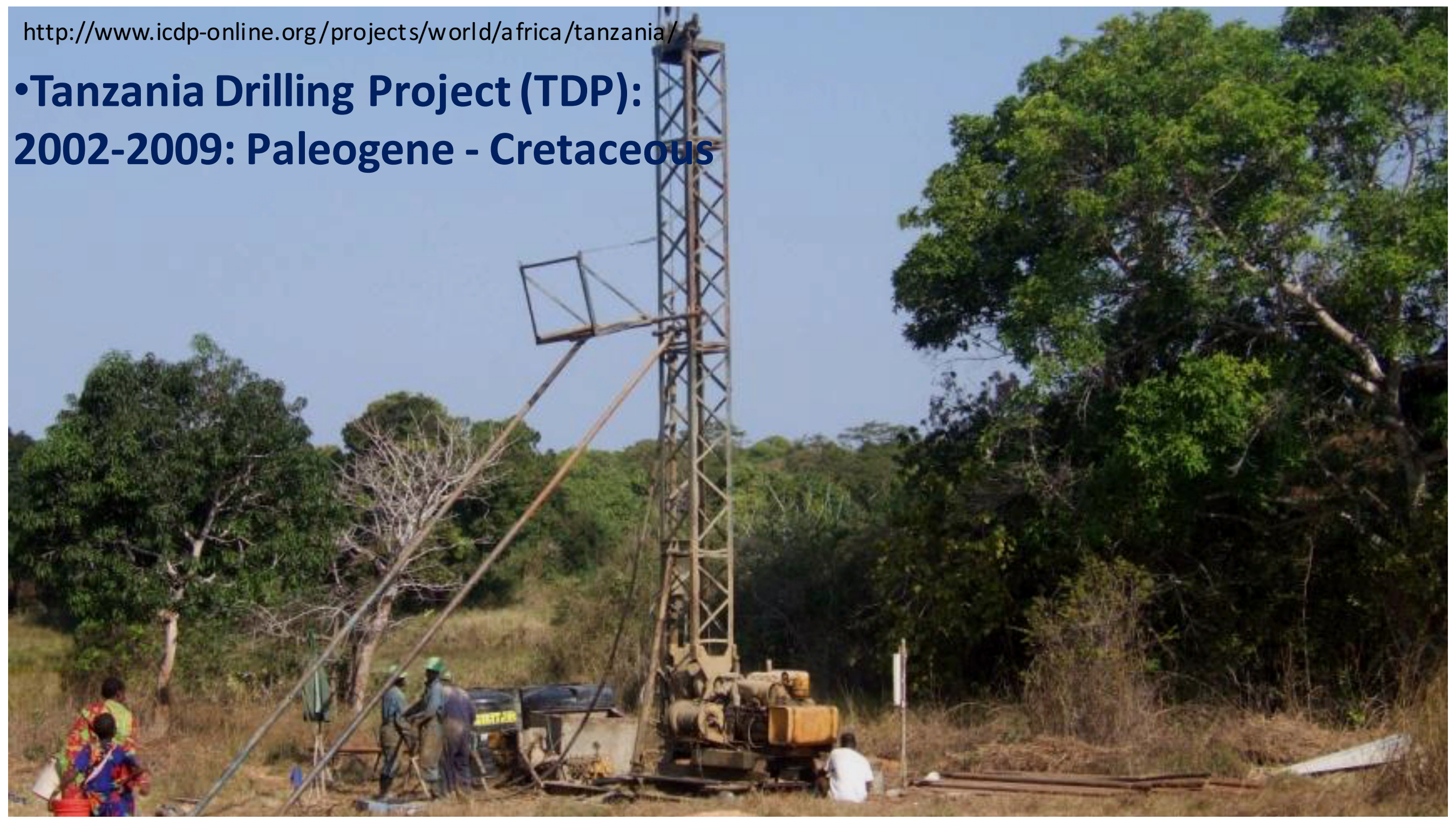



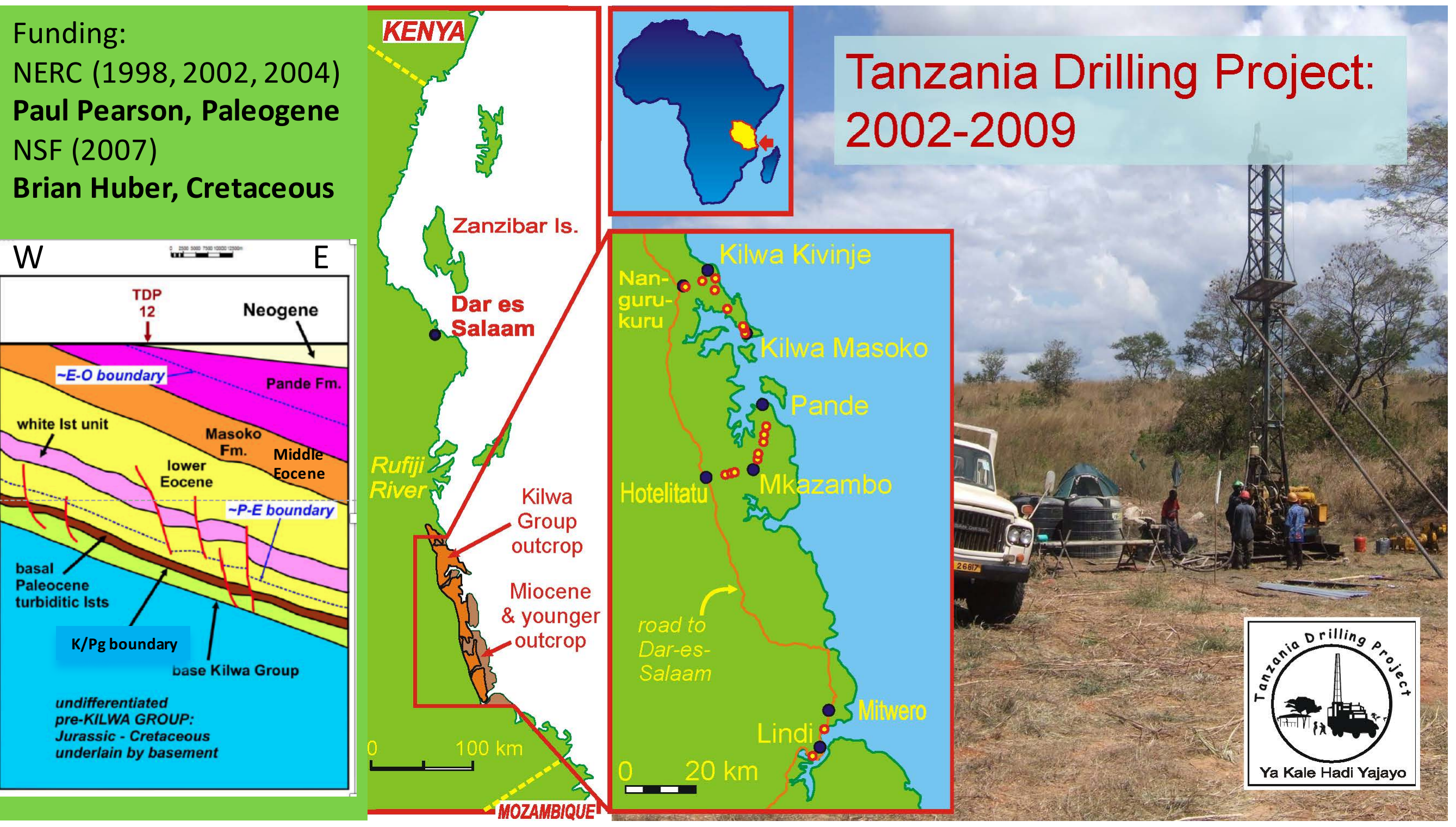


\section{0 sites. Remote locations...}
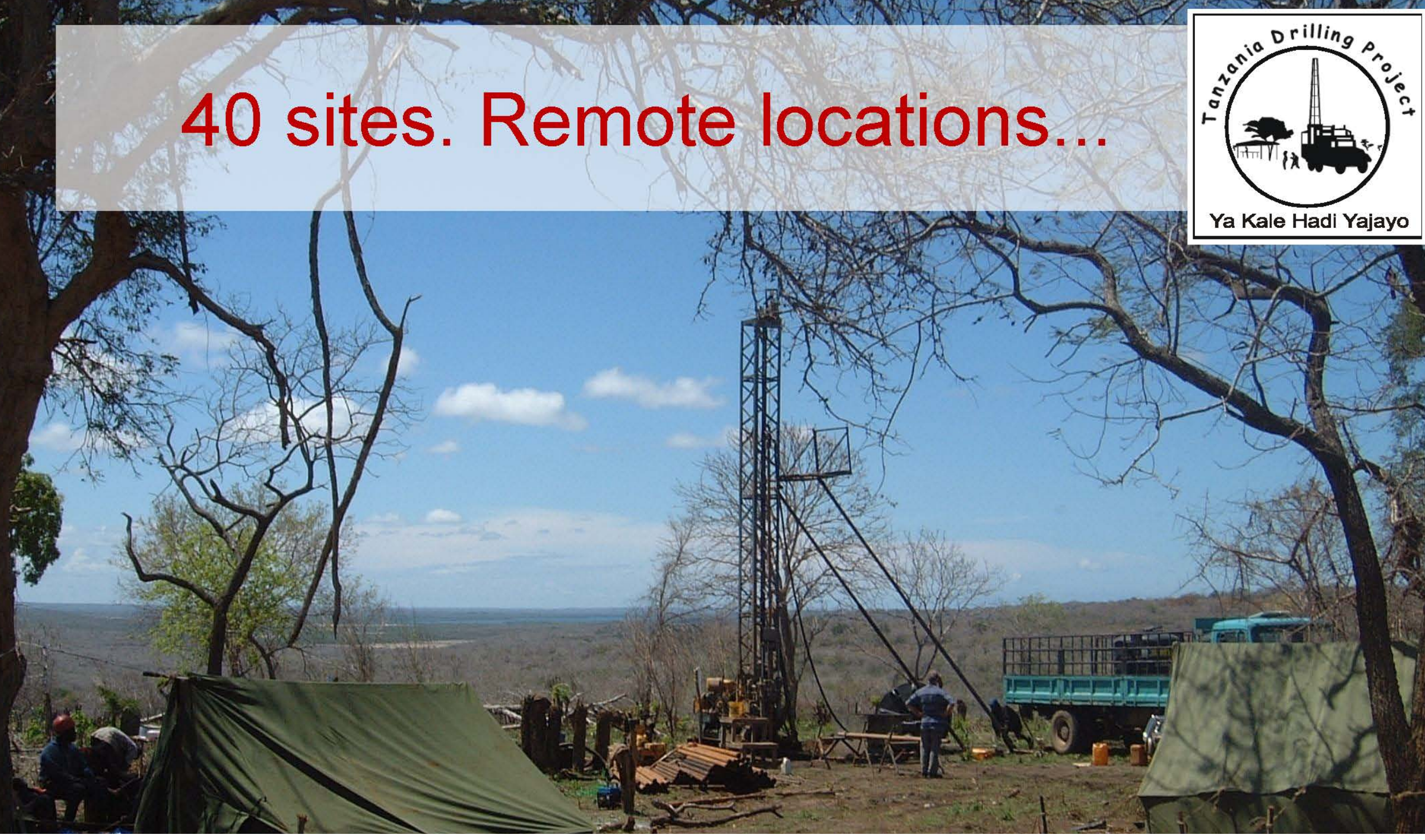


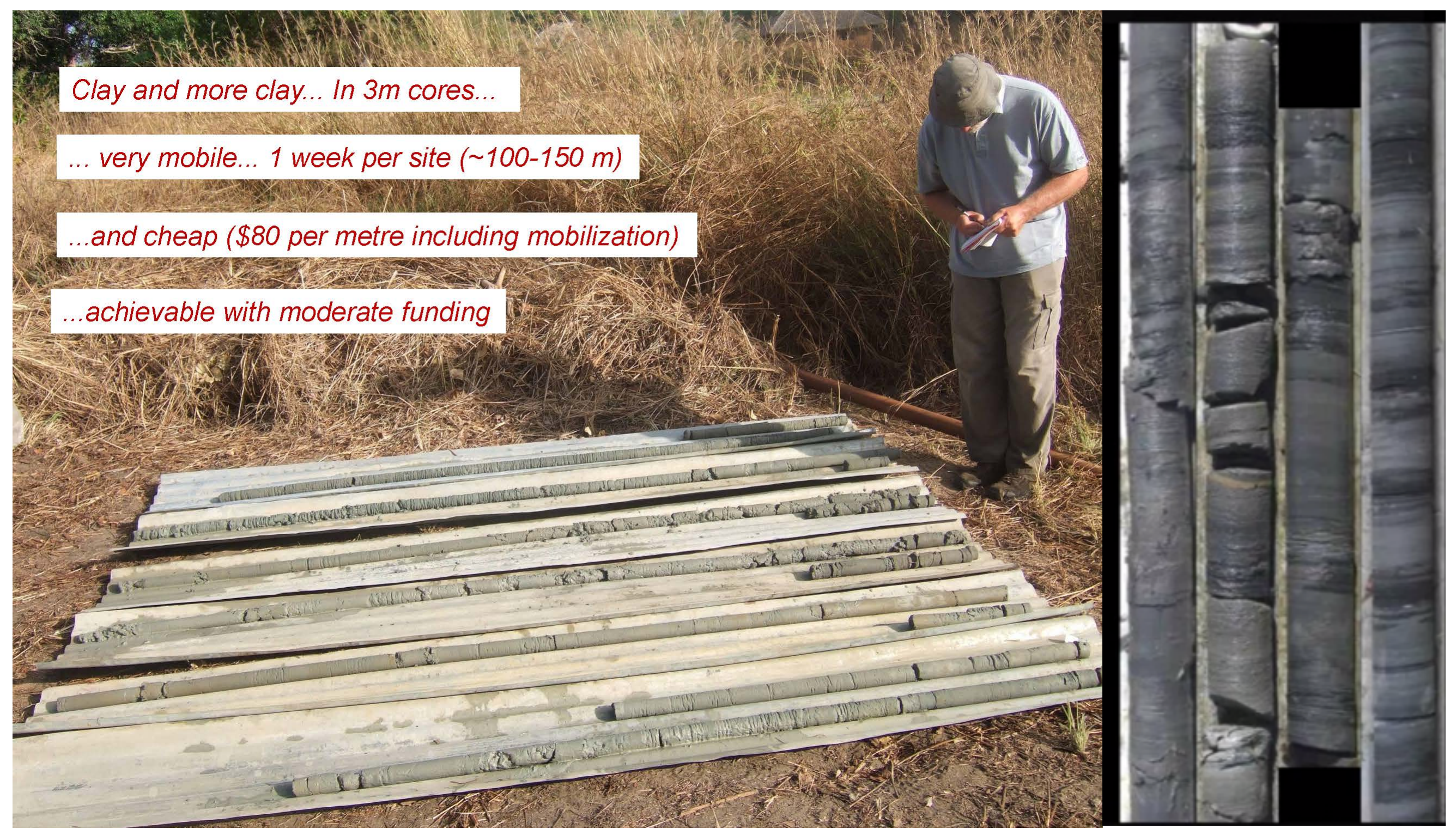




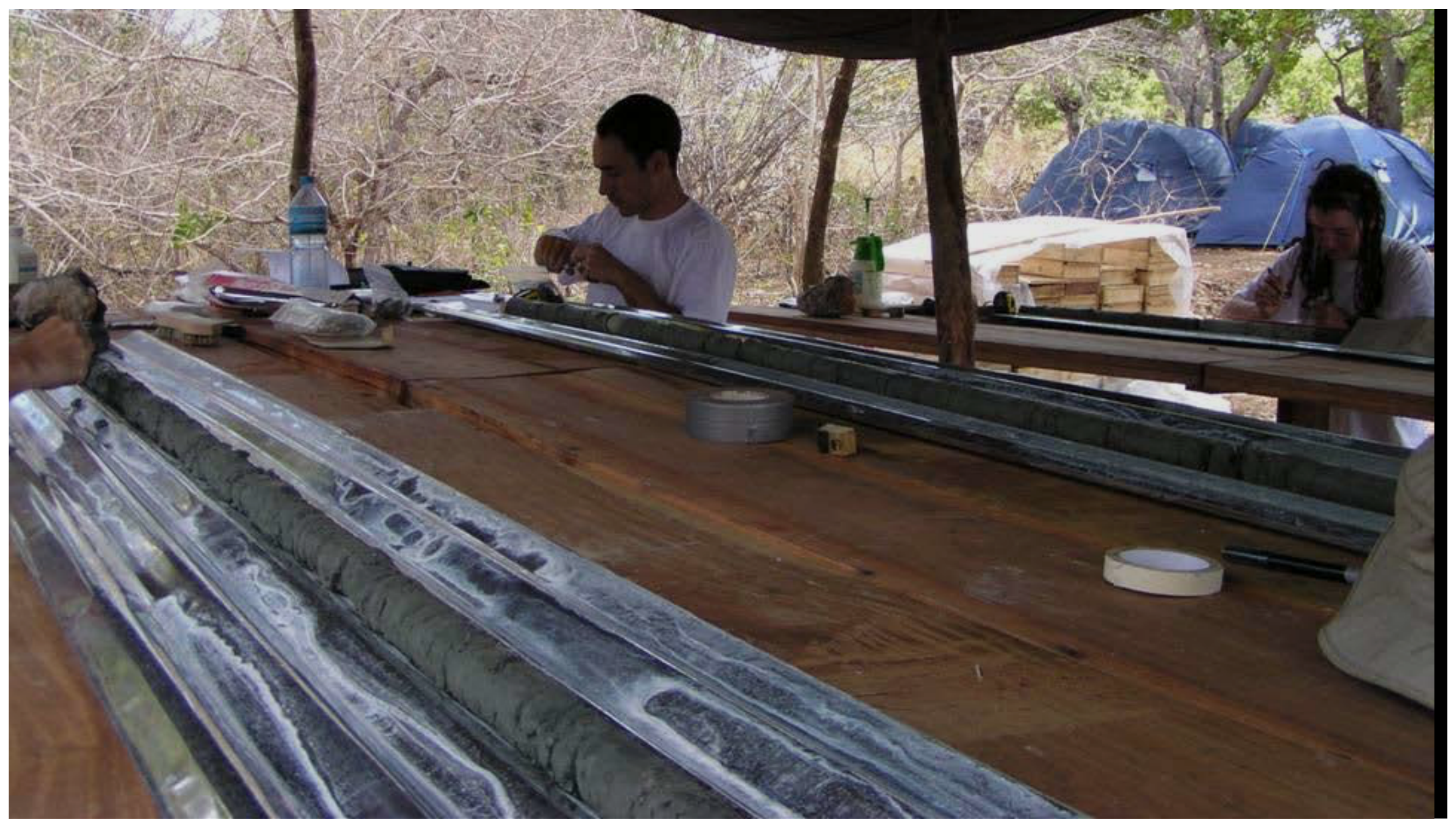




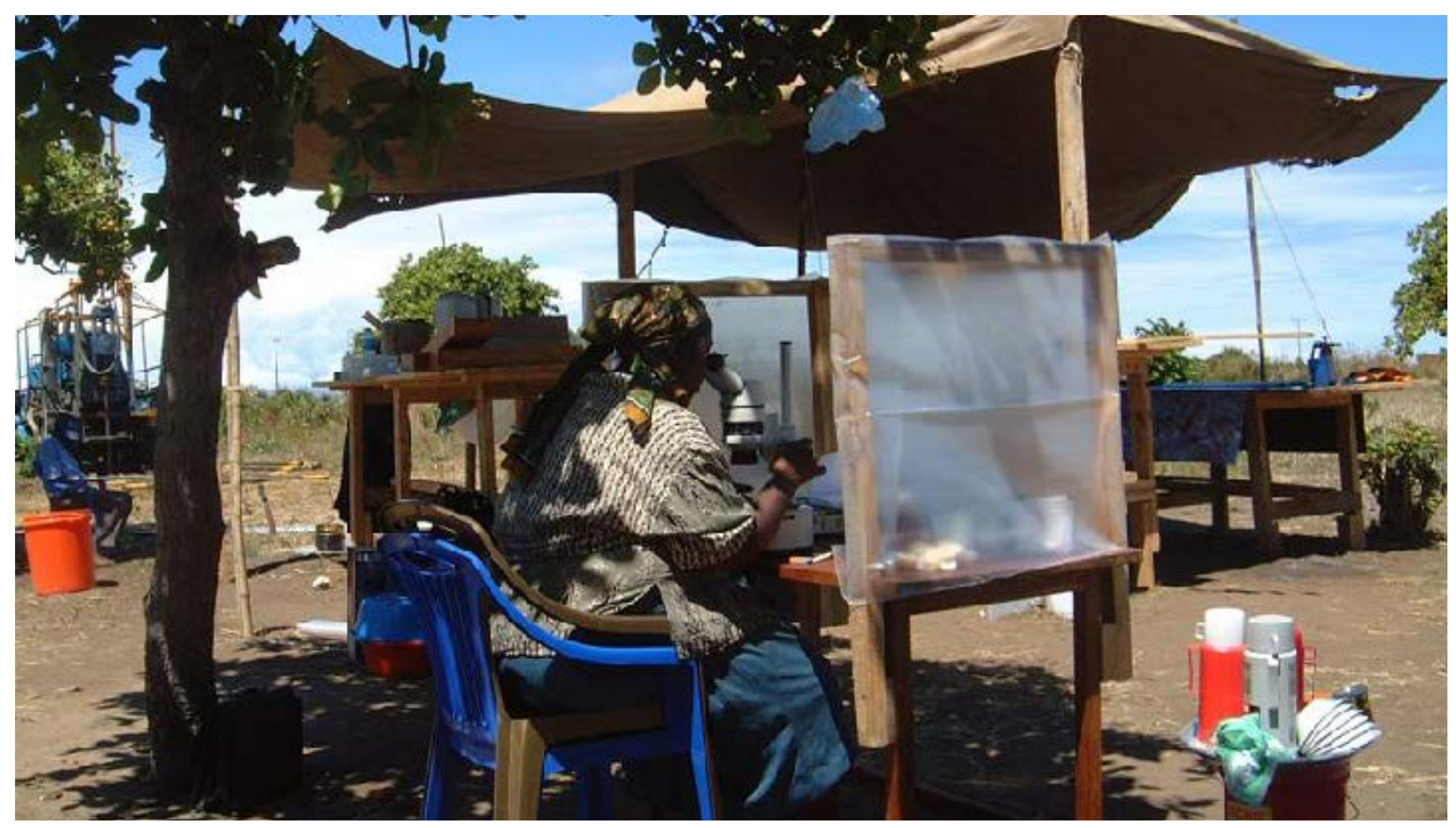




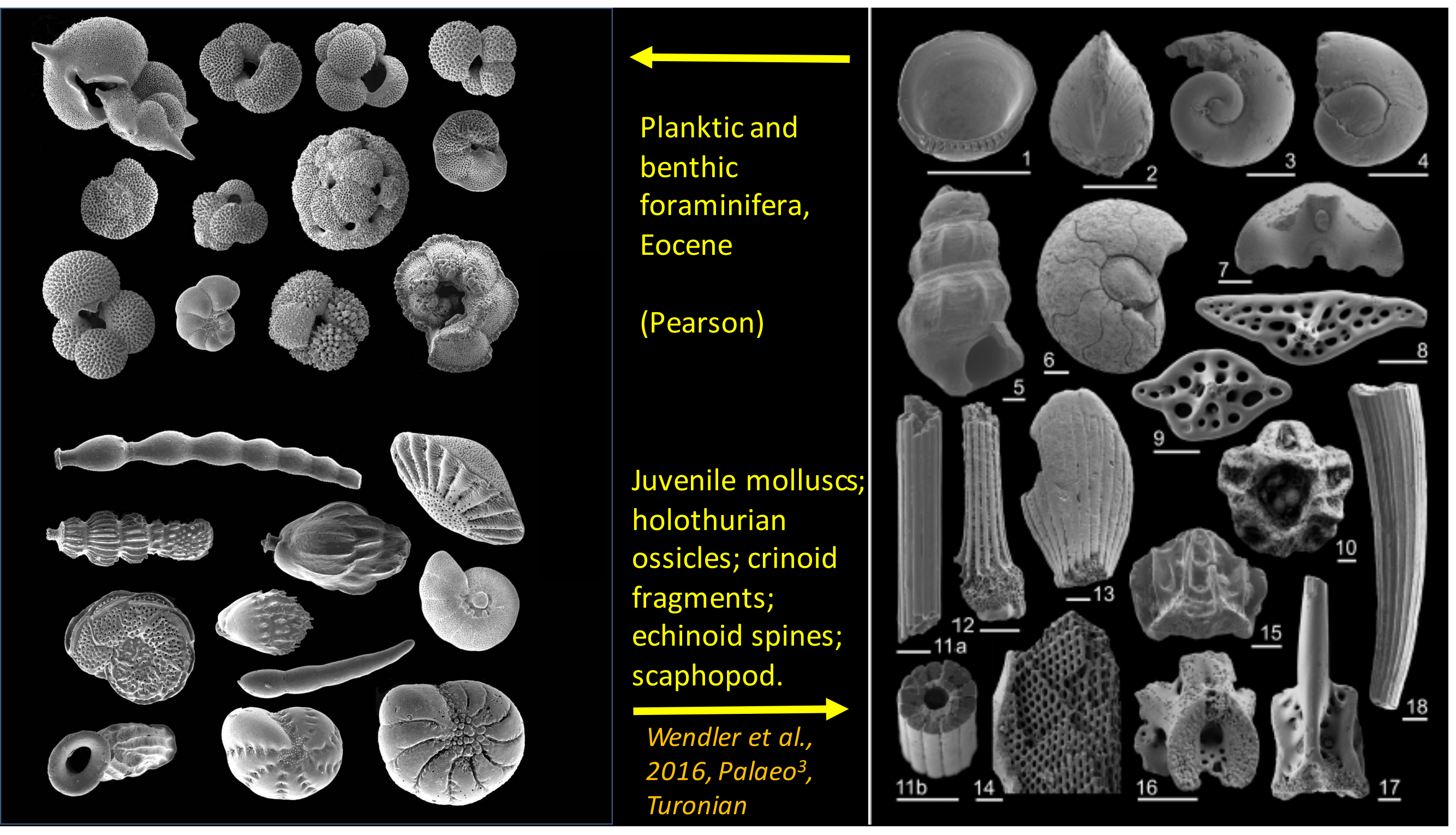




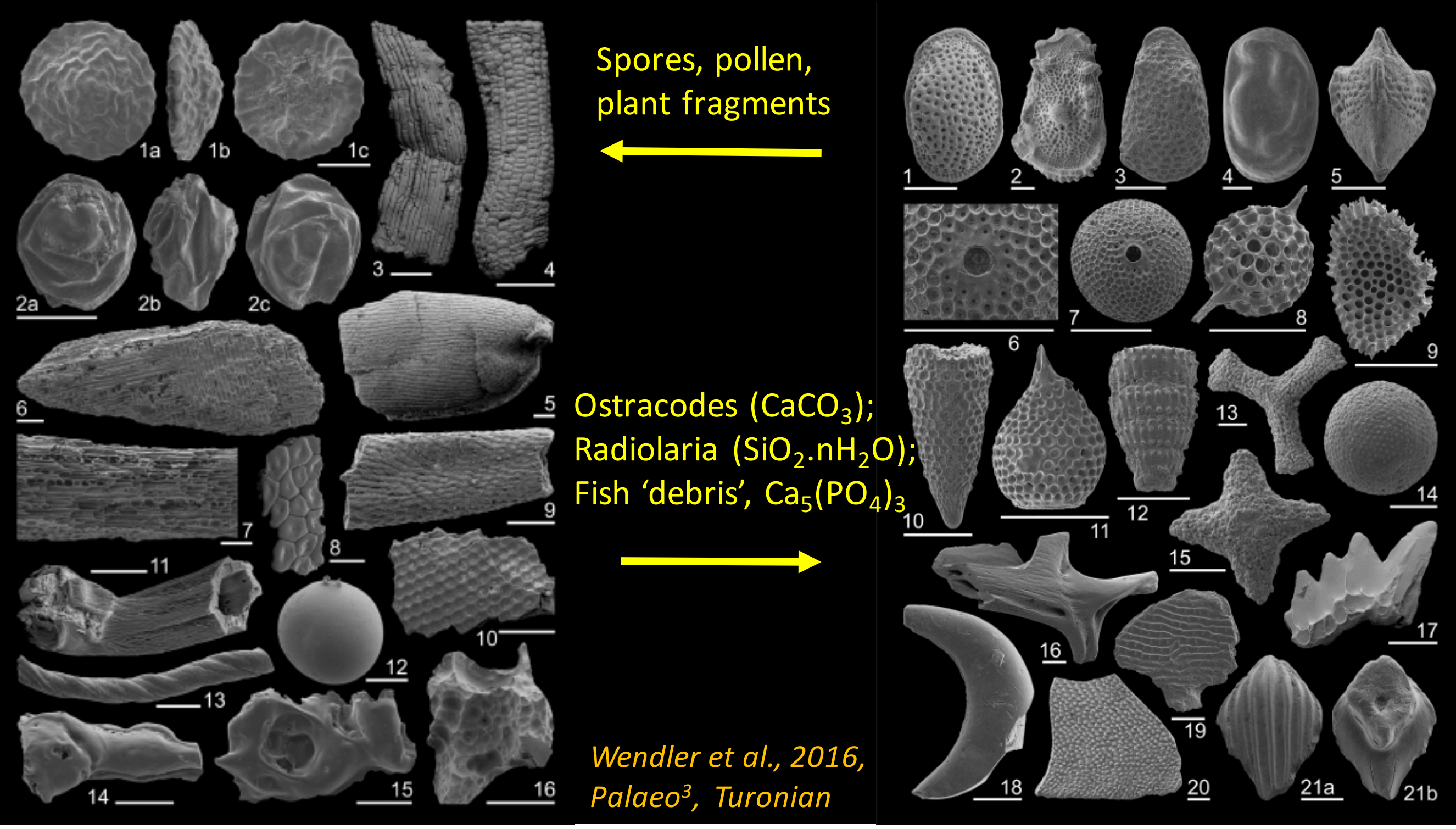


TDP 2/10/3 polar fraction -n-Alkenols, even over odd predominance $\downarrow$ Terrestrial origin
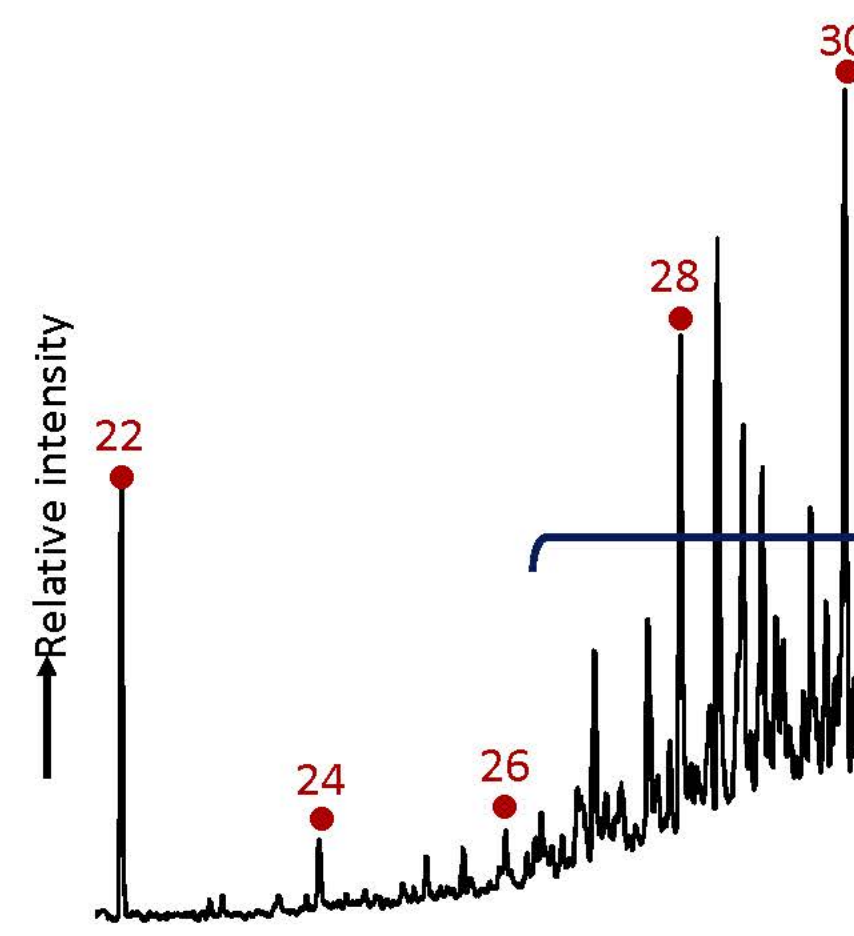

30

\section{Organic} molecules-

biomarkers

Mainly Triterpenoids,

Hopanoids and steroids

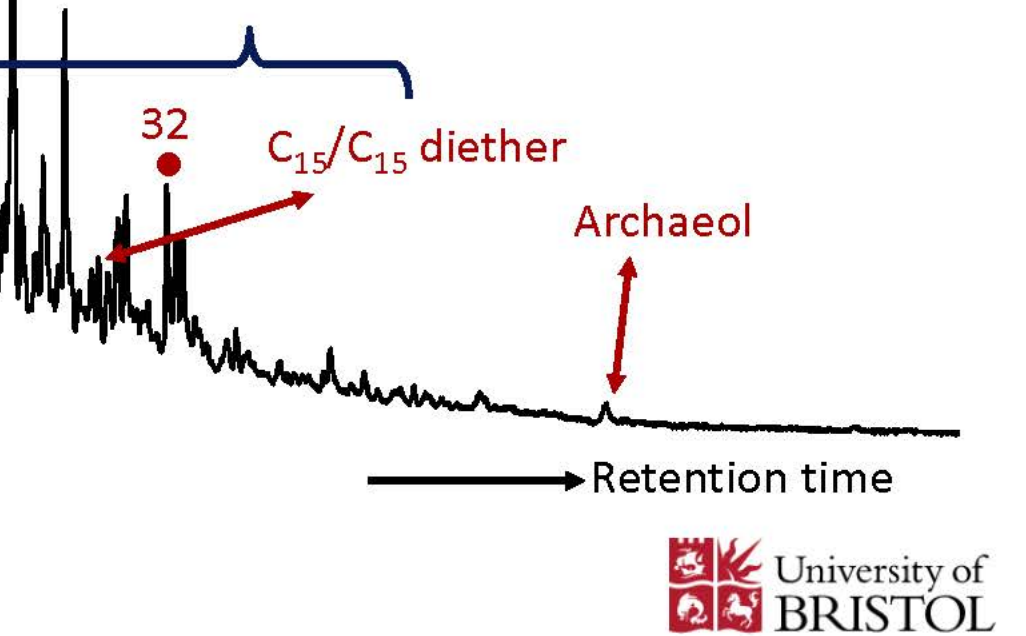




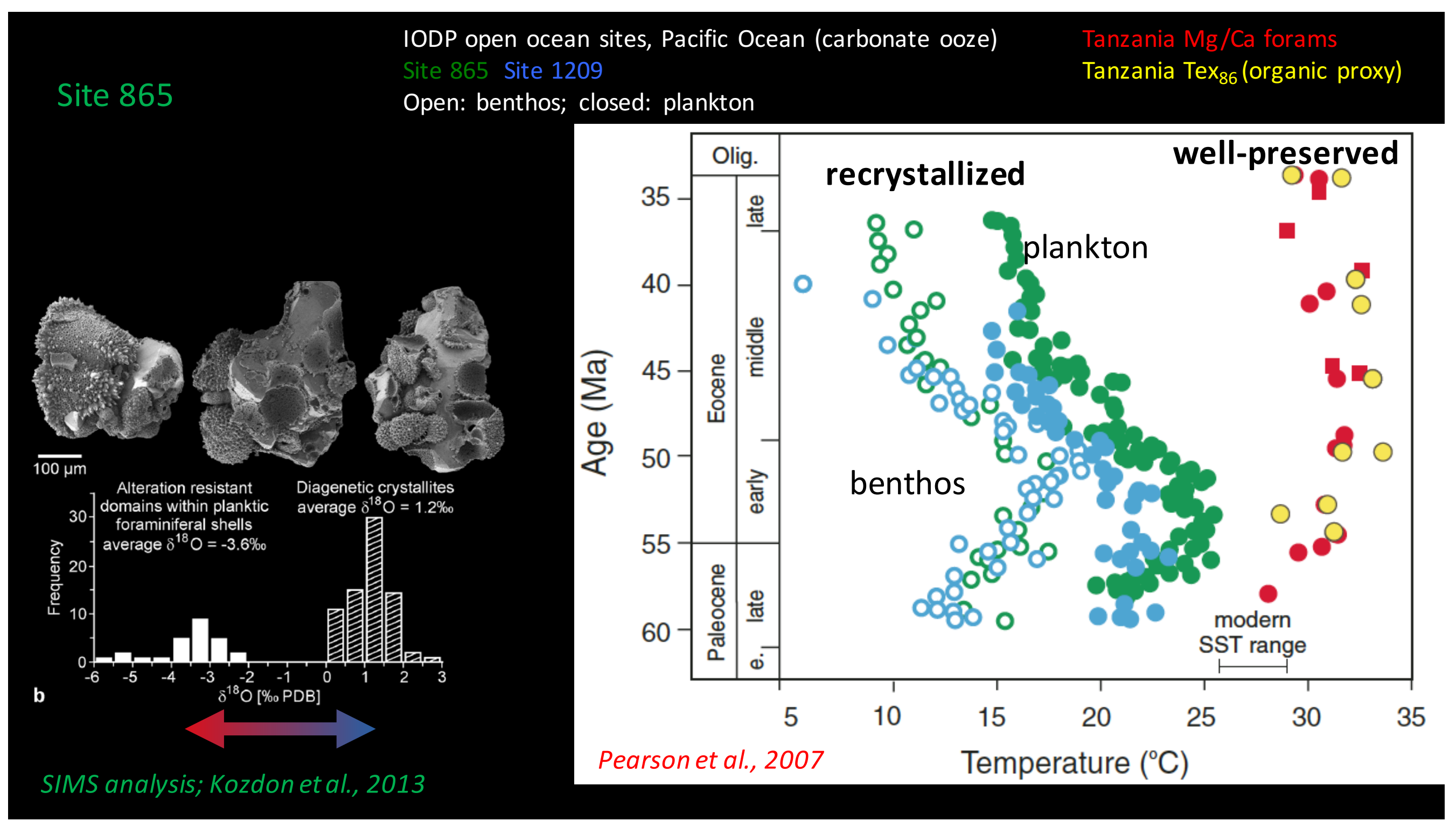



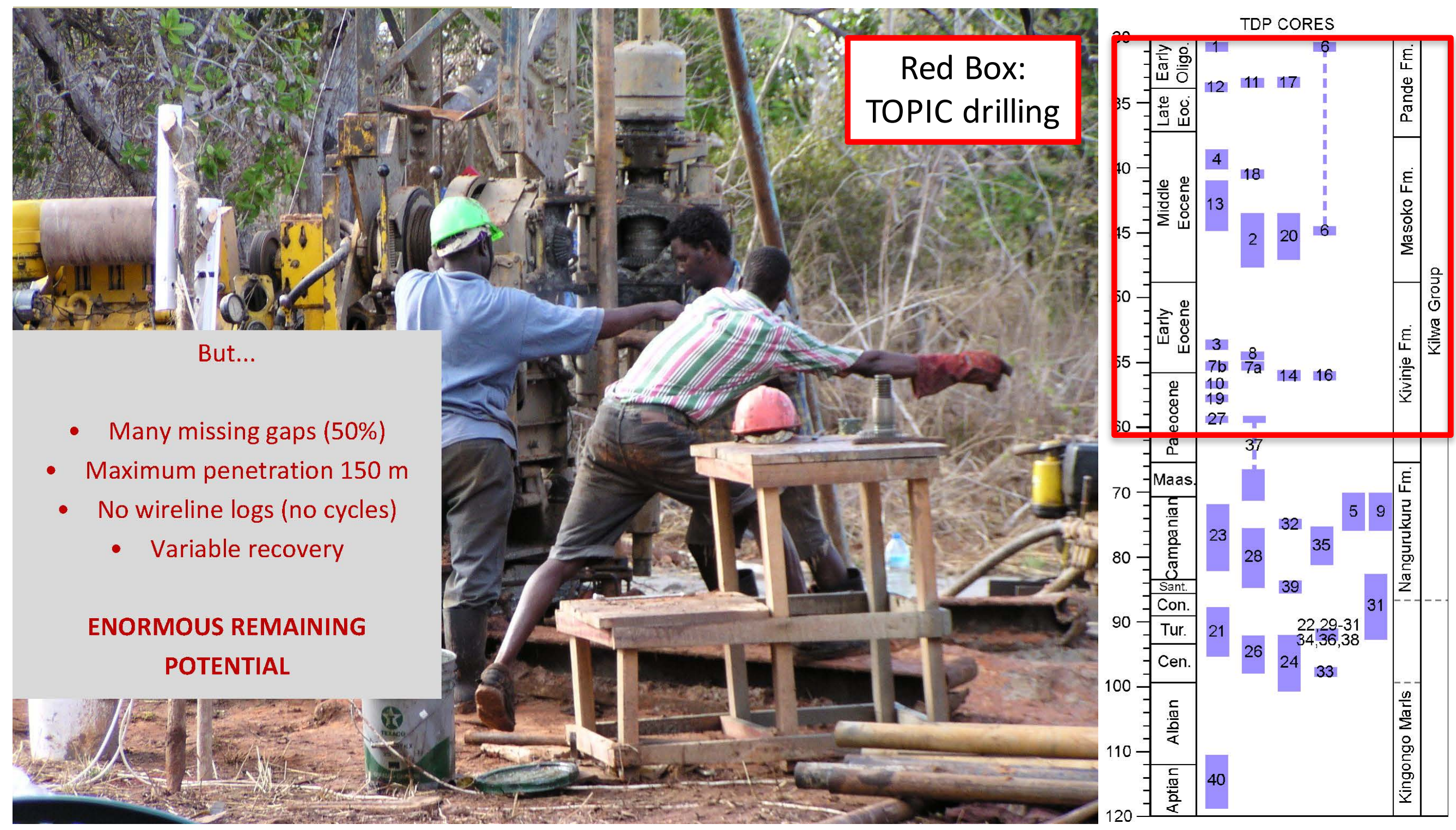


\section{POTENTIAL:}

-Deposits very thick (several $\mathrm{km}$ ), homogeneous (claystone), Aptian through middle Miocene. -Tropical - subtropical (8-105, Eocene $\left.17-19^{\circ} \mathrm{S}\right)$ : reconstruct conditions close to the warm endmember of the global climate state - Hemipelagic deposits, deep water (200-500 m, possibly deeper), oceanic 'blue water' microfossil assemblage and bathyal benthos.

-Sufficiently close to the continent $(50-70 \mathrm{~km}$ from the paleoshoreline) for terrestrial material such as soil bacterial biomarkers, pollen and woody matter and shallow water microfossils (larger foraminifera).

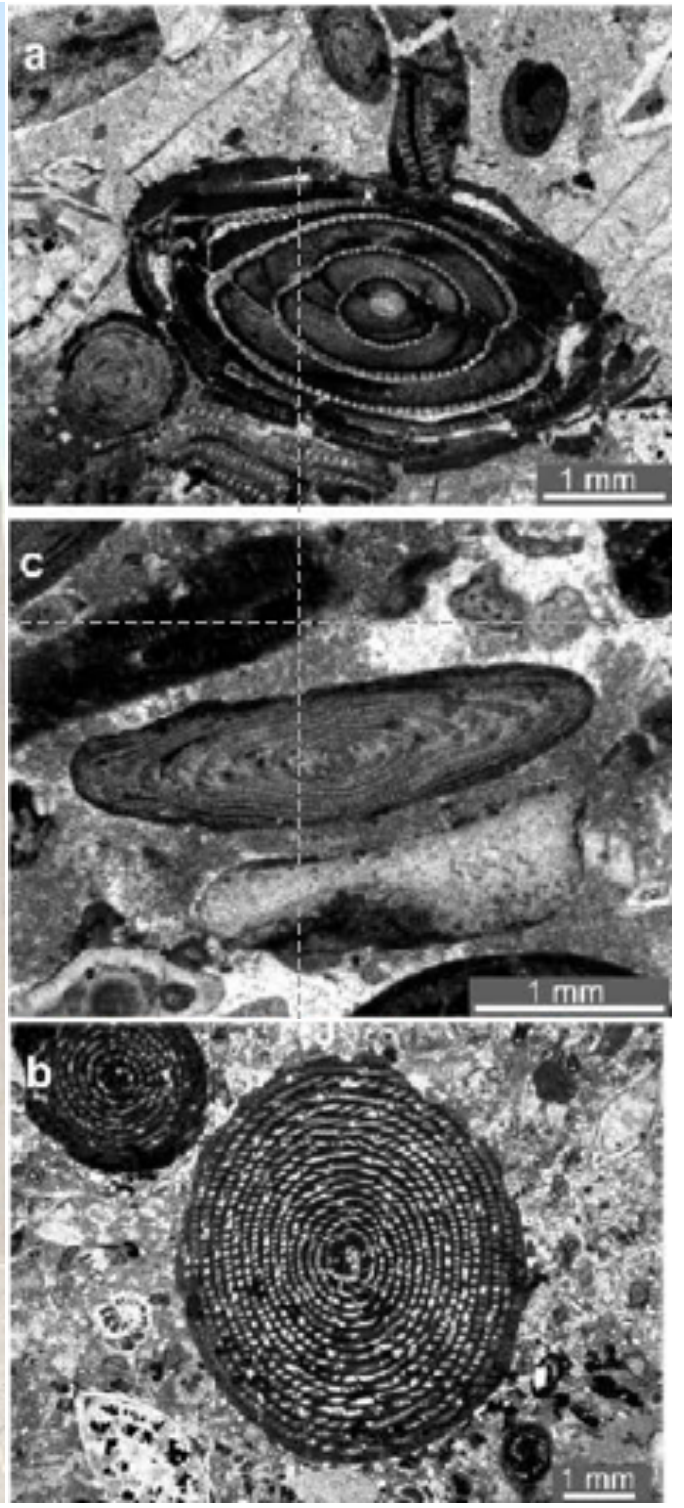




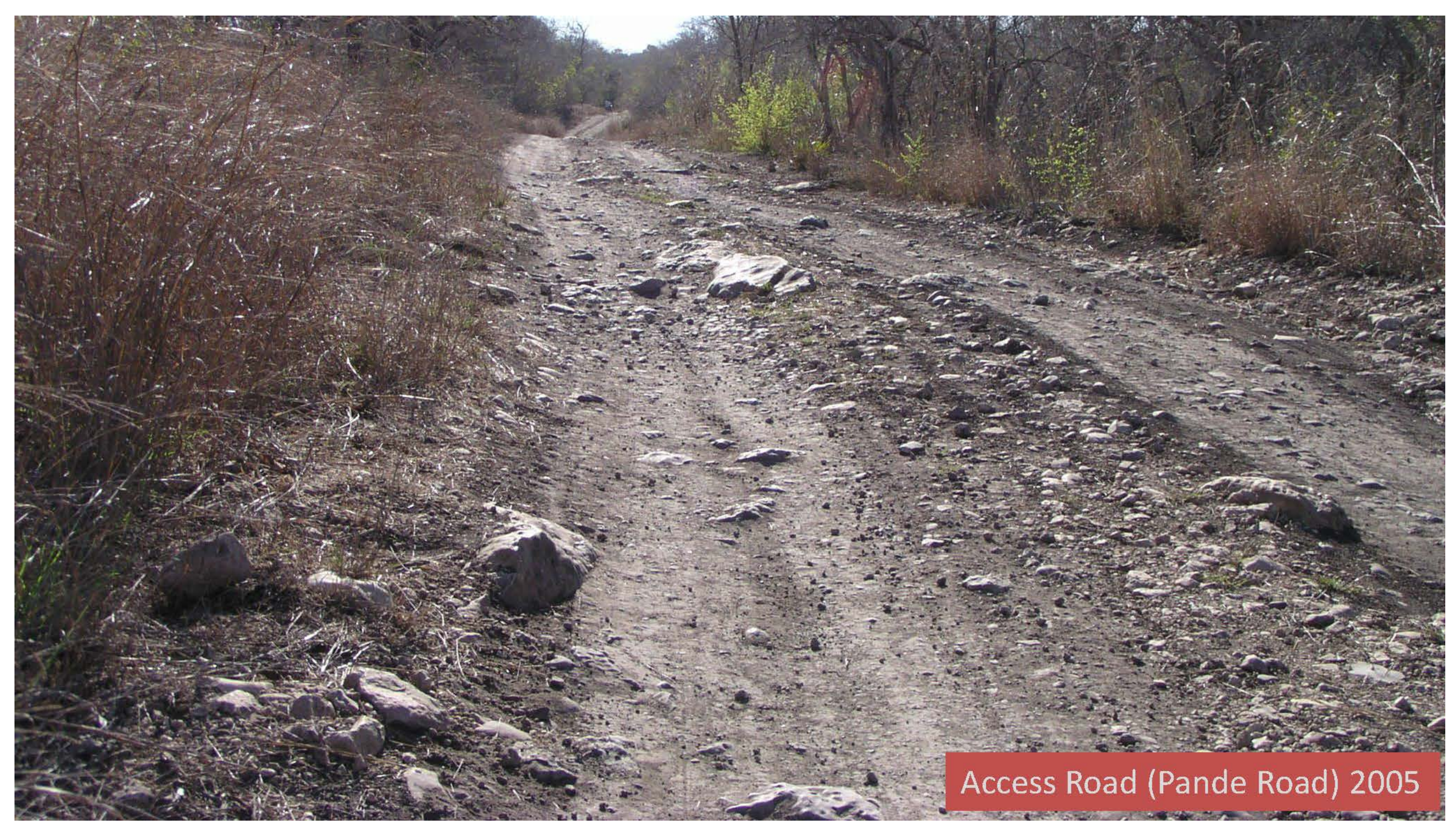




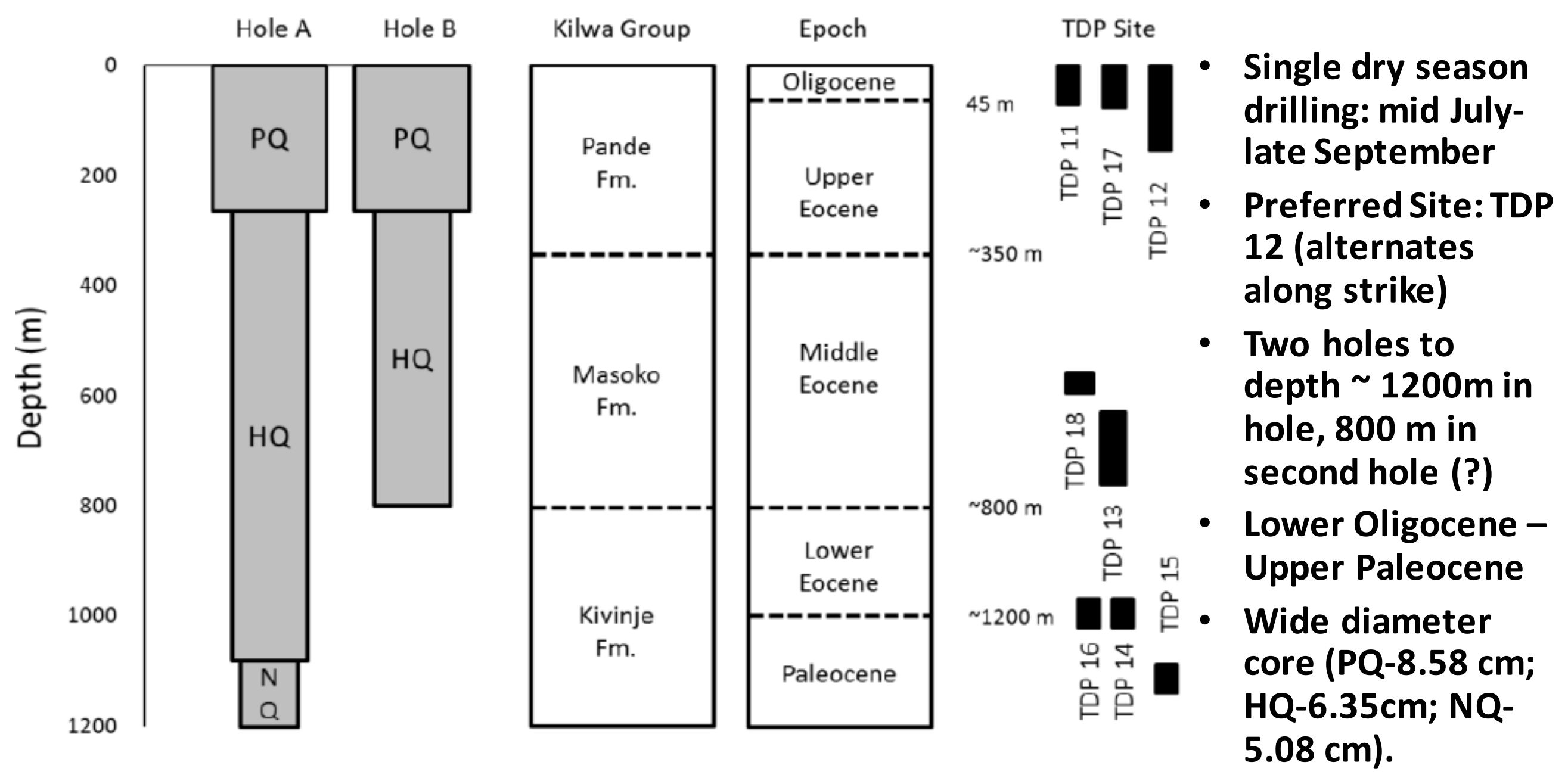




\section{TANZANIA ONSHORE PALEOGENE INTEGRATED CORING (TOPIC)}

- How extreme did climatic conditions become in the tropics, in the oceans and on land?

- To what extent did atmospheric $\mathrm{CO}_{2}$ and global temperature co-vary during intervals of global warmth?

-What was the response of the marine and terrestrial biota to extreme climate states and intervals of climate change?

- Is the paleoclimate forcing and response we infer from the sediment record consistent with the predictions of General Circulation Models (GCMs) and Earth System Models?

-'Deep biosphere' in mudstones with very little pore fluid migration geologically quiescent sub-surface environment. 


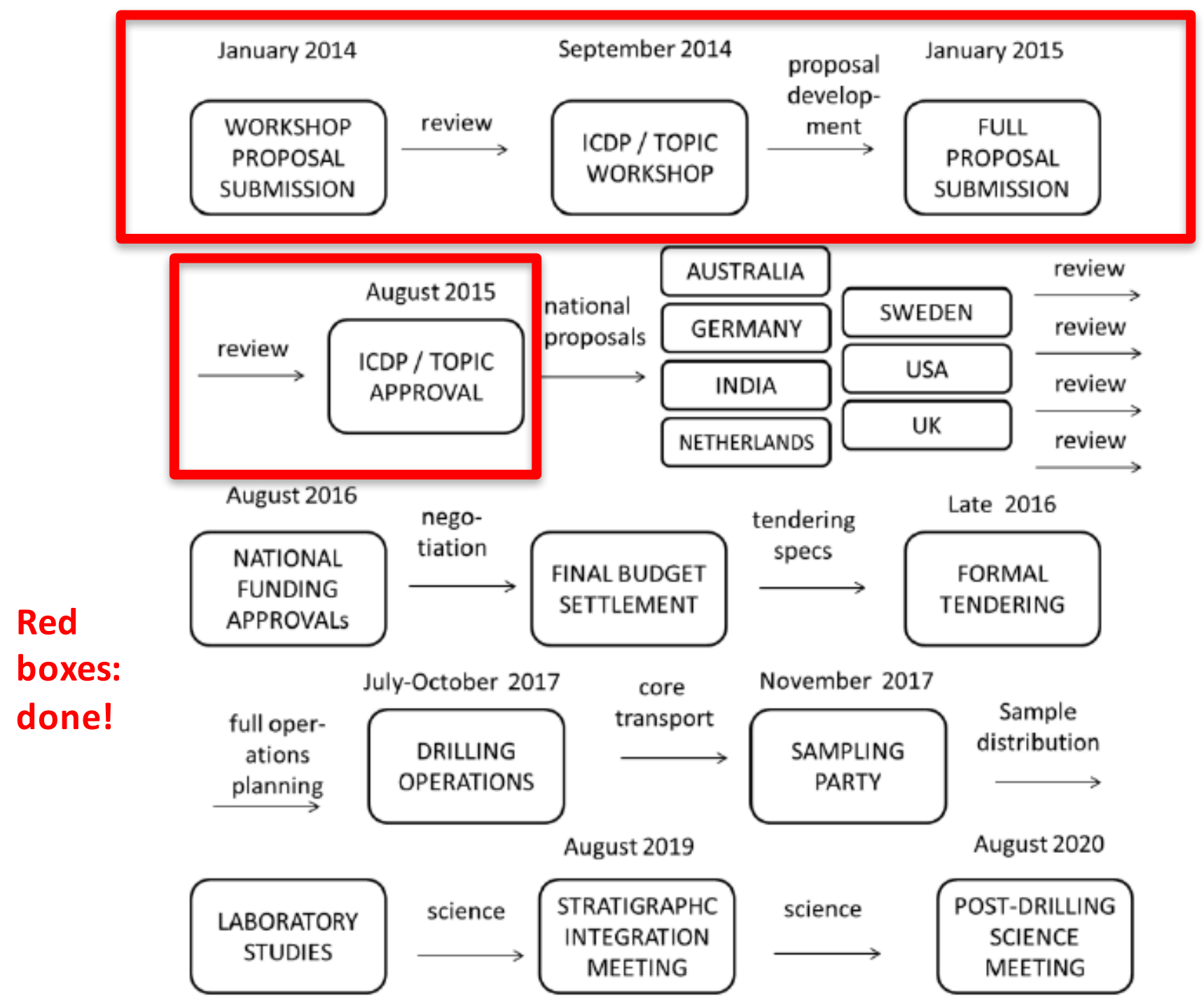


- Field sampling: 1998-2000

- Tanzania Drilling Project (TDP): 2002-2009: Paleogene-Cretaceous

- Workshop Dar-es-Salaam: 10-12 September 2014

- Proposal submitted to ICDP: January 2015, Paleocene-Oligocene sediment (65-30 million years old) at a single core site $(1200 \mathrm{~m})$

- ICDP provisional decision to fund: June 2015 ( \$ 1M out of \$2.9M)

- Addendum submitted: September 2015; ICDP approved

- Proposals submitted to NERC (UK) not funded 


\section{Thank you.}

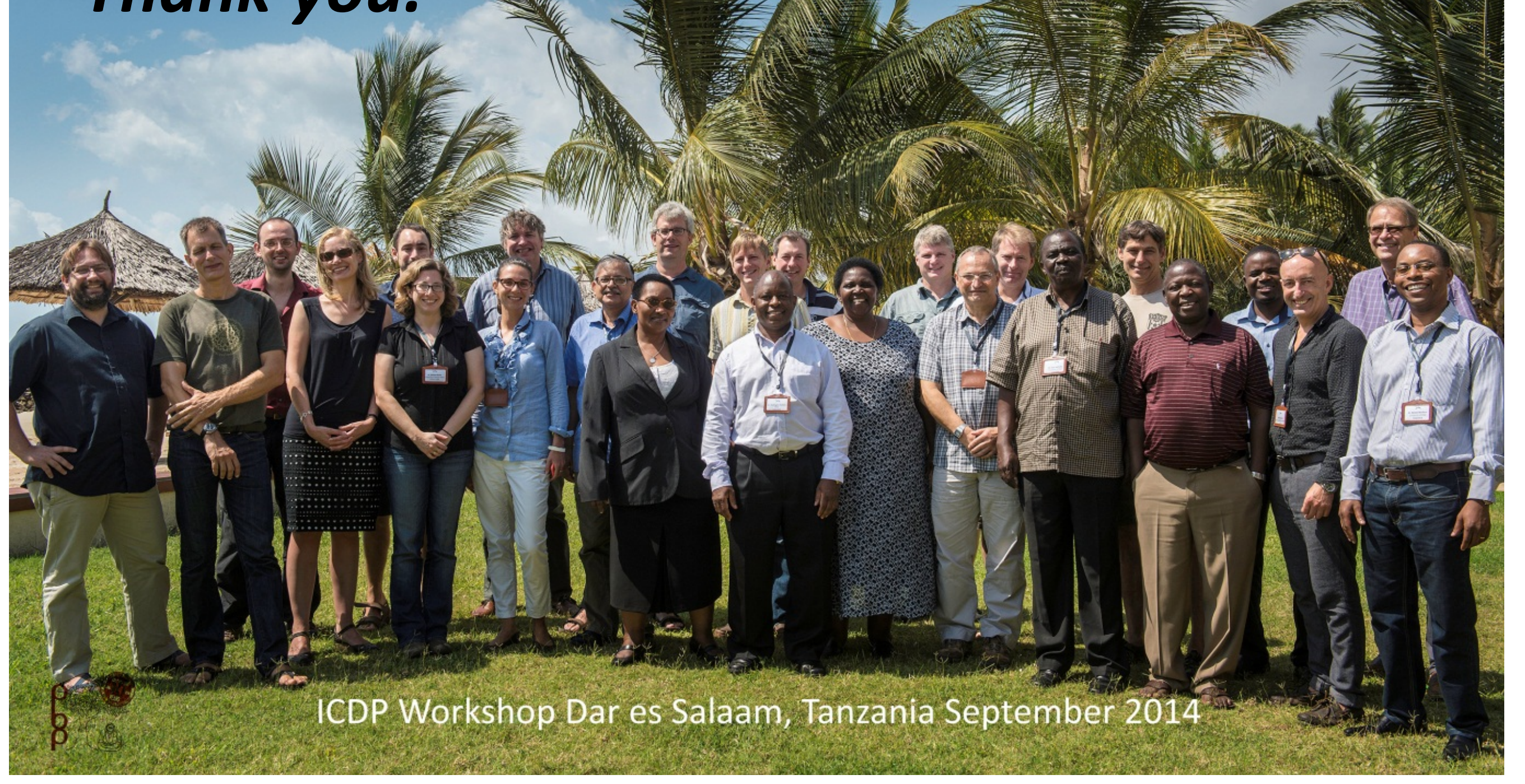

